Published by Al-Nahrain College of Medicine P-ISSN 1681-6579

E-ISSN 2224-4719

Email: iraqijms@colmed-alnahrain.edu.iq

http://www.colmed-alnahrain.edu.iq

http://www.iraqijms.net

Iraqi JMS 2019; Vol. 17(1)

\title{
The Vitro Study Effect of Ginger Extracts on Fungal Isolated from A Suppurative Otitis Media and Externa
}

\author{
Azhar A.F. Al-Attraqchi ${ }^{1} P h D$, Hayder B. Sahib² PhD, Jaafer M.K. Al-Hasseni ${ }^{3}$ FICMS, Maha M. \\ Mohammed MSC
}

${ }^{1}$ Dept. of Microbiology, College of Medicine, Al-Nahrain University, Baghdad, Iraq, ${ }^{2}$ Dept. of ????, College of Pharmacy, Al-Nahrain University, Baghdad, Iraq, ${ }^{3}$ Dept. of Surgery, College of Medicine, Al-Nahrain University, Baghdad, Iraq

\begin{abstract}
Background Otitis media is a group of complex inflammatory disorders affecting the middle ear, which can be acute or chronic. Otitis externa is an inflammation on the skin of the external auditory canal usually associated with secondary bacterial and/or fungal infection of macerated skin and subcutaneous cellular tissue.

Objective To investigate the effect of ginger extracts on fungal isolates from patients suffering from otitis.

Methods Two hundred patients suffering from suppurative otitis media and externa who attended to ENT Department, Al-Imamein Al-Kadhimein Medical City enrolled in this study from November 2016 to the end of April 2017, included patients all age groups with discharging ear. All specimens were transported to the laboratory for processing and investigations at the same day. The powder of ginger rhizomes soaked with the solvent and left in a shaking water bath at $40{ }^{\circ} \mathrm{C}$ for 24 hours, and then filtered using Whatmann's filter paper No.1 for clear extract. Each extract was concentrated using a rotary evaporator with vacuum to get the final crude extract $\backslash$; after the procedure of ginger extract was done, this extract was taken and tested for bacterial and fungal isolates from patients with otitis.

Results Results revealed that acute otitis media consisted of about 96 (48\%), while chronic suppurative otitis media about 75 (37.5\%). Otitis externa was less common infection among the other types of otitis $29(14.50 \%)$. The most fungal isolates were Candida parapsilosis. In addition, there is a significant effect of (chloroform, methanol, and aqueous) extract of ginger on pathogenic fungi.

Conclusion Ginger extracts have been showed evident zones of inhibition effect on pathogenic fungi by chloroform more than ethanol, with less effect by aqueous extract.

Keywords

Citation Otitis externa, otitis media, ginger extract

Al-Attraqchi AAF, Sahib HB, Al-Hasseni JMK, Mohammed MM. The vitro study effect of ginger extracts on fungal isolated from a suppurative otitis media and externa. Iraqi JMS. 2019; 17(1): 4-11. doi: 10.22578/IJMS.17.1.2
\end{abstract}

List of abbreviations: $A O M=$ Acute otitis media, $\mathrm{CSOM}=$ Chronic suppurative otitis media, $\mathrm{OE}=$ Otitis externa, $\mathrm{DMSO}=$ Dimethyl sulfoxide

\section{Introduction}

7 he infection of ear is a common clinical problem throughout the world and the major cause of preventable hearing loss in the developing world. Ear infection can be classified as acute otitis media (AOM), chronic suppurative otitis media (CSOM), and otitis externa (OE) ${ }^{(1)}$. Otitis media is an infection of middle ear caused by bacteria, fungi and virus resulting in inflammation of mucosal lining (2). AOM is inflammation of the middle ear with the production of otorrhea and other symptoms but with less than two weeks of duration (3). In 
developing countries, the natural course of the disease is different, leading to purulent otitis often with perforation and further complications ${ }^{(4)}$. CSOM is a name given to long standing inflammatory disease affecting mucoperiosteal lining of the middle ear (5). Inflammation of the cutis and sub cutis of the external auditory canal is a primary symptom in acute otitis externa ${ }^{(6)}$. OE, also called swimmer's ear, involves diffuse inflammation of the external ear canal that may extend distally to the pinna and proximally to the tympanic membrane ${ }^{(7)}$. The treatment for ear infection mainly depends on antibiotic therapy. Within consideration the major public health challenge for antibiotic resistant bacteria ${ }^{(8)}$. So herbal medicine and homeopathy are interchangeable practiced together and sometimes confused (9). Plant derived products have been used for medicinal purposes for centuries. In traditional Indian medicine Zingiber officinale and many other herbs have been used as medicine (10). Today, the interest for use of herbs instead of chemical drugs is increasing because of lesser side effects ${ }^{(11)}$. Rhizome part of ginger genus: Zingiber is extensively employed in medicine for the management of different diseased conditions ${ }^{(12)}$. Zingiber aceae is among the plant families that are widely distributed throughout the tropics, particularly in Southeast Asia (13). Ginger is a strong antioxidant substance and may either mitigate or prevent generation of free radicals. This natural herbal product is known to have powerful antifungal properties ${ }^{(14)}$. It is also having broad spectrum of biological activities includes antioxidant, antimicrobial, antitumor or antidiabetic effects ${ }^{(15)}$.

The objective of this study was to investigate the effect of ginger extracts on fungal isolates from patients suffering from otitis.

\section{Methods}

\section{Samples collection:}

Two hundred patients suffering from CSOM and OE who attended to Al-Imamein Al-Kadhimein Medical City were enrolled in this study from November 2016 to the end of April 2017, included patients in all age groups who attended ENT Department with ear symptoms. The majority of patients were from Baghdad and its suburbs. All swabs specimens were collected from each patient in clean sterile swabs. These were labeled with code number and name. All swabs samples were taken at same day that had been transported to laboratory for investigations.

\section{Preparation of ginger extract}

Five hundred grams of dried rhizomes of ginger (Zingiber officinale) were purchased from local markets in Baghdad -Iraq and was identified by the National Iraqi Institute for Herbs. The dried rhizomes grind into very fine powder using a heavy-duty grinder. The powder of ginger rhizomes, then divided into 12 portions, each portion extracted sequentially with three solvents beginning with the non-polar solvent and ascending to the most polar solvent respectively (chloroform, methanol and distilled water) with a ratio of 1:7 W/V (30 gm of powder/ $210 \mathrm{ml}$ of solvent); the extraction repeated twice for each solvent and the process of extraction used was the cold method, i.e., Maceration. The powder of ginger rhizomes soaked with the solvent according to the ratio mentioned previously and left in a shaking water bath at $40{ }^{\circ} \mathrm{C}$ for 24 hours and then filtered using Whatmann's filter paper No. 1 for clear extract. Each extract was concentrated using a rotary evaporator with vacuum to get the final crude extract. The extract powder was weighed and kept in sterile bottles, labeled accordingly and stored in the refrigerator, according to Muslim et al. (2012) (16). One gm of the crude extracts of chloroform, methanol and aqueous extracts were dissolved in $10 \mathrm{ml}$ Dimethyl sulfoxide (DMSO) as stock solutions.

\section{Antifungal test of extracts using agar well diffusion method}

The antifungal activity of different extracts against fungi was evaluated by using agar well diffusion method (17). Isolated colonies were selected from Sabouraud's dextrose agar plate cultures and transferred to $3 \mathrm{ml}$ of $0.85 \%$ normal saline of a density equivalent to the 
turbidity of the (0.5) McFarland standards. A sterile cotton swab was dipped into the fungal suspension; excess fluid inoculum from the swab was removed by pressing the swab firmly on the side wall of the tube above the fluid level, streaking of the inoculum was done over the entire sterile agar surface. This procedure was repeated by streaking 2 more times, rotating the plate approximately $60^{\circ}$ each time to ensure an even distribution of inoculum as a final step, the rim of the agar was swabbed. The plates were left at room temperature for 15 minutes to allow any excess surface moisture to be absorbed. Wells of $5 \mathrm{~mm}$ were punctured with the help of a sterilized cork-porer into the pre-solidified Mueller Hinton agar plates containing the test organism. Using the micropipette, $20 \mu \mathrm{l}$ of each extract (chloroform, methanol, and aqueous) was poured into the different wells of the inoculated plates. DMSO well used as a negative control, fungal plates were incubated at $37{ }^{\circ} \mathrm{C}$ for $72 \mathrm{hrs}$. The diameters of zones of inhibition were measured, later on.

\section{Statistical analysis}

Data of this study samples were entered using EPI INFO7 Windows Version and analyzed by using statistical package for social sciences (SPSS) version 20. Descriptive statistics were presented as frequencies, percentage (\%), means and standard deviation (SD). Chi square test was used to estimate the association between two categorical variables. Level of significance of $\leq 0.05$ was considered as significant. Analysis of variance (ANOVA) used for comparison among more the two groups. A paired samples $\mathrm{T}$ test used for comparison between two groups.

\section{Results}

\section{Gender and age distribution of patients with ear infection}

A total of 200 patients suffering from otitis were enrolled in this study. The mean age of patients was (30.04), ranged from 7 days-80 years old. It was found that a half of patients were males as 109 (54.50\%) and 91 (45.50\%) were females. Two hundred patients with otitis were classified into Seven age groups per decade (Table 1).

Table 1. Classification of patients with otitis regarding age groups

\begin{tabular}{ccc}
\hline Age group & No. & Percentage $\%$ \\
\hline $\mathbf{1 0}$ years & 50 & 25.0 \\
$\mathbf{1 1 - 1 2}$ years & 23 & 11.5 \\
$\mathbf{2 1 - 3 0}$ years & 35 & 17.5 \\
$\mathbf{3 1 - 4 0}$ years & 25 & 12.5 \\
$\mathbf{4 1 - 5 0}$ years & 30 & 15.0 \\
$\mathbf{5 1 - 6 0}$ years & 21 & 10.5 \\
$\mathbf{2 0}$ years & 16 & 8.0 \\
Total & 200 & $100 \%$ \\
\hline
\end{tabular}

\section{Isolation and identification of fungi}

Two hundred ear swab samples were collected from patients with otitis have been cultured on Sabouraud's dextrose agar, the results revealed that thirty-two samples were positive for fungi (Table 2).

Fungal isolates from patients with otitis:

Table (3) summarized fungal isolates from patients with otitis as discussed below. 
Table 2. Fungal species isolated from ear discharge

\begin{tabular}{ccc}
\hline Age group & Frequency & Percentage \% \\
\hline Aspergillus spp. & 4 & 2.0 \\
Candida parapsilosis & 20 & 10.0 \\
Candida glabrata & 1 & 0.5 \\
Microsporum audouinii & 2 & 1.0 \\
Penicillium spp. & 1 & 0.5 \\
Trichophytone & 4 & 2.0 \\
mentogrophte & & \\
No growth & 168 & 84.0 \\
Total & 200 & $100 \%$ \\
\hline
\end{tabular}

Table 3. Percentages of fungal isolates from patients with otitis

\begin{tabular}{ccccc}
\hline Fungal isolate & AOM & CSOM & OE & Total \\
\hline Aspergillus spp. & $2(2.1 \%)$ & $2(2.7 \%)$ & $0(0.0 \%)$ & $4(2.0 \%)$ \\
Candida parapsilosis & $8(8.4 \%)$ & $7(9.3 \%)$ & $5(17.2 \%)$ & $20(10.0 \%)$ \\
Candida glabrata & $1(1.0 \%)$ & $0(0.0 \%)$ & $0(0.0 \%)$ & $1(0.5 \%)$ \\
Microsporum audouinii & $2(2.1 \%)$ & $0(0.0 \%)$ & $0(0.0 \%)$ & $2(1.0 \%)$ \\
Penicillium spp & $1(1.0 \%)$ & $0(0.0 \%)$ & $0(0.0 \%)$ & $1(0.5 \%)$ \\
Trichophytone mentogrophte & $3(3.1 \%)$ & $1(1.3 \%)$ & $0(0.0 \%)$ & $4(2.0 \%)$ \\
No growth & $79(82.3 \%)$ & $65(86.7 \%)$ & $24(82.8 \%)$ & $168(84.0 \%)$ \\
Total & $96(100 \%)$ & $75(100 \%)$ & $29(100 \%)$ & $200(100 \%)$ \\
p value & & \multicolumn{3}{c}{$\mathbf{0 . 7 3 3}$} \\
\hline
\end{tabular}

Antifungal activity of ginger extracts fungal isolates

The antifungal activities of ginger extract with (chloroform, methanol, and aqueous) have been tested against pathogenic fungal species isolates from patients with otitis (Table 4). In case of Aspergillus spp., chloroform extract revealed the larger mean of diameter of inhibition zones as $(6.00 \pm 7.12 \mathrm{~mm})$ followed by aqueous extract of ginger when the mean of diameter of inhibition zones as $(4.00 \pm 4.62 \mathrm{~mm})$, while methanol extract showed no effect. In Candida parapsilosis, chloroform extract was the strongest among the others when the mean of diameter of inhibition zones was $(11.14 \pm 5.05$ $\mathrm{mm})$, followed by methanol extract when the mean of diameter of inhibition zones was $(7.57 \pm 4.08 \mathrm{~mm})$, then aqueous extract of ginger as $(4.86 \pm 4.51 \mathrm{~mm})$. In Candida glabrata, chloroform extract was the strongest among the others when the mean of diameter of inhibition zones was $(12 \mathrm{~mm})$, followed by methanol extract, the mean of diameter of inhibition zones was $(8 \mathrm{~mm})$, then aqueous extract of ginger as $(7 \mathrm{~mm})$. Microsporum audouinii was inhibited by chloroform extract when the mean of diameter of inhibition zones as $(22.50 \pm 16.26$ $\mathrm{mm}$ ), followed by this obtained by aqueous extract of ginger as $(12.50 \pm 0.71 \mathrm{~mm})$, and then by this obtained by methanol extract as $(7.00 \pm 0$ $\mathrm{mm})$. Chloroform extract was the only effective agent against Trichophytone mentogrophte when the mean of diameter of inhibition zone was $(8.50 \pm 5.74 \mathrm{~mm})$, while each of aqueous extract of ginger and methanol extract showed no effect. 
Table 4. Antifungal activities of each of aqueous, methanol, and chloroform extract of ginger against pathogenic fungi isolated from patients with otitis

\begin{tabular}{ccccc}
\hline & \multicolumn{3}{c}{ Mean of the diameter of inhibition Zones (mm) } \\
\hline Fungal culture & Chloroform & Methanol & Aqueous & $\begin{array}{c}\text { Negative } \\
\text { control }\end{array}$ \\
\hline Aspergillus spp. & & & & $0.00 \pm 0$ \\
Candida parapsilosis & $6.00 \pm 7.12$ & $0.00 \pm 0.00$ & $4.00 \pm 4.62$ & $0.00 \pm 0$ \\
Candida glabrata & $11.14 \pm 5.05$ & $7.57 \pm 4.08$ & $4.86 \pm 4.51$ & 0.00 \\
Microsporum audouinii & 12.0 & 8.0 & 7.0 & $0.00 \pm 0$ \\
Trichophytone mentogrophte & $8.50 \pm 16.26$ & $7.00 \pm 0$ & $12.50 \pm 0.71$ & $0.00 \pm 0$ \\
\hline
\end{tabular}

\section{Discussion}

Gender and age distribution of patients with ear infection

In the present study, results indicated the percentage of infected males were 109 (54.50\%) and females were $91(45.50 \%)$ out of 200 patients with otitis, hence there was significant difference between males and females infection rate upon existing both in different condition, geographical variation, male may be more exposed to different conditions in work such as dust, humidity, and may be more actively involved in outdoor activities, hence to be more exposed to contaminated environment, in females wearing of scarfs may be considered an important factor to decrease infection, in addition to the differences in the No. of each involved in the study. This result agrees with other obtained by Almamory and Kamal in 2014 (17) who mentioned that the rate of ear infection in males was higher than females, while disagree with this obtained by Khammas and Abbas in $2010{ }^{(18)}$ who mentioned that the rate of ear infection in females was higher than those of males. In the current study and according to the result of age of patients with ear infection revealed that all age groups could be developed otitis with significant differences, the highest infection rate was (50) cases occurred in the age group $(\leq 10)$ years, the plausible explanation of these result that children and infants may have low resistance to infection, and because of relative short and straight Eustachian tube ${ }^{(19)}$, the lower immune system of children compared to adults, and the fact that bacteria adhere better to epithelial cells of children than adults (20). This result agrees with other study, done by Jayakar et al in $2014^{(21)}$ who proved that there were significant differences in the distribution of age in ear infection.

\section{Fungal isolates from patients with otitis}

Through this work it was found that fungi have a good role in otitis. The highest percentage of infection which caused by Candida parapsiolosis as $20(10.0 \%)$, this agree with Al Husaini and Abu-serag in $2016^{(22)}$ who proved that Candida parapsilosis was the predominant species as (31.95\%). Trichophytone mentogrophte consist of $4(2.0 \%)$, then Microsporum audouinii as 2 (1.0\%), followed by Penicillium spp. and Candida glabrata when the percentage of infection was 1 (0.5\%). These results agree with Aremu and Alabi in $2011{ }^{\text {(23) }}$ who found the most fungi caused CSOM was Candida spp. followed by Aspergillus spp. In case of acute otitis media, it was found that the most common fungi were Candida spp. followed by Aspergillus spp., this disagree with that obtained by Almamory and Kamal in 2014 (17) who proved the highest frequency of infection by Aspergillus spp. and the lowest percentage was due to Alternaria spp. When there were no any isolates of Candida spp. The plausible explanation of this phenomenon that humidity, low hygienic condition may have a role of developing these cases of infection. Regarding Penicillium spp. the percentage of infection was only $1(0.5 \%)$ and this agree with Kiakojuri et al in 2015 (24) who found only one case of otitis caused by Penicillium spp. Also, it was found that each of 
Trichophytone mentogrophte and Microsporum audouinii were responsible of AOM when there were no previous compatible studies to compare this result with. Ear self-cleaning is the most common predisposing factor for infection because this will lead to remove the protective ear wax ${ }^{(25)}$.

\section{Antifungal activity of ginger extract versus chloroform, methanol, and aqueous}

Table (4), showed Aspergillus spp. it has been found that chloroform extract had the larger inhibition zones of mean of diameters as $(6.00 \pm 7.12 \mathrm{~mm})$ followed by aqueous extract with a mean of diameters of inhibition zones as $(4.00 \pm 4.62 \mathrm{~mm})$, while methanol extract showed no effect at all. This study disagrees with this by Ikegbunam et al in $2015{ }^{\text {(26) }}$ who found that the aqueous extract of ginger had no effect on Aspergillus spp. and agree with Abd Elkhalek et al in $2016^{(27)}$ who mentioned that ginger aqueous extract have an effect on Aspergillus spp., these incompatibilities in results may due the differences in the local prepared ginger, technique used into specific variation among the local isolates of Aspergillus spp. In Candida parapsilosis, chloroform extract was the strongest among the other when the mean of the diameter of inhibition zones was $(11.14 \pm 5.05 \mathrm{~mm})$, followed by methanol extract when the mean of diameter of inhibition zones was $(7.57 \pm 4.08 \mathrm{~mm})$, then aqueous extract of ginger as $(4.86 \pm 4.51 \mathrm{~mm})$. In Candida glabrata, chloroform extract was the strongest among the other when the mean of the diameter of inhibition zones was $(12 \mathrm{~mm})$, followed by methanol extract the mean of diameter of inhibition zones was $(8 \mathrm{~mm})$, then aqueous extract of ginger as $(7 \mathrm{~mm})$, these results disagree with those obtained by Jasim et al (2013) ${ }^{(28)}$ who mentioned that aqueous extract of ginger have no effect on each of Candida parapsilosis, and on Candida glabrata at all. This discrepancy may due to the above reasons. The growth of Microsporum audouinii was inhibited by chloroform extract when the mean of diameter of inhibition zones as $(22.50 \pm 16.26$ $\mathrm{mm}$ ), flowed by this obtained by aqueous extract of ginger as $(12.50 \pm 0.71 \mathrm{~mm})$, then by this obtained by methanol extract as $(7.00 \pm 0$ $\mathrm{mm})$, this study with the first applying this agents against Microsporum audouinii as antifungal, the higher activity of the chloroform extract could be attributed to the presence of more phytochemicals than in this methanol extract. Chloroform extract was the only effective agent against Trichophytone mentogrophte when the mean of diameter of inhibition zone was $(8.50 \pm 5.74 \mathrm{~mm})$, while each of aqueous extract and methanol extract of ginger showed no effect at all and this may because the nature of the structure of hyphae of Trichophytone mentogrophte that may be resist to methanol and aqueous extract and sensitive to chloroform extract because chloroform extract has more phytochemicals. There is no such compatible study to compare these results with.

This study had concluded that the most frequent fungi isolated from patients with otitis it was Candida parapsilosis, followed by Aspergillus spp. The percentage of AOM is the highest among the other types of infection and the lower one is otitis externa. The age group $\leq 10$ years old were the highest among other groups in developing otitis. Chloroform extract of ginger is the most effective as an antifungal followed by methanol extract, while aqueous extract to less evident of inhibition zones.

This study recommended that in vivo Study of ginger extracts to evaluate its less toxicity to be used as a drug of choice in otitis for human in future instead of antimycotics because it has a dual activity (antibacterial and Microsporumaudouinii antifungal) and because it is less toxic than chemicals.

\section{Acknowledgments}

The authors are grateful to all staff member of Medical Microbiology Department, College of Medicine, Al-Nahrain University for their help and cooperation. Special thanks for the staff member of ENT Department in Al-Imamein AlKadhimein Medical City for their kind assistance in samples collection.

\section{Author contribution}

Mohammed: Msc student, Dr. Al- Attraqchi: Supervision, Dr. Al-Hassani: Sample collection, 


\author{
Dr. Sahib: consultation of the pharmaceutical \\ part of research.
}

\section{Conflict of interest}

The author declares that they have no competing interests.

\section{Funding}

Self-finding.

\section{References}

1. Argaw-Denboba A, Abejew AA, Mekonnen AG. Antibiotic-resistant bacteria are major threats of otitis media in wollo area, northeastern Ethiopia: A ten-year retrospective analysis. Int J Microbiol. 2016; 2016: 8724671. doi: 10.1155/2016/8724671.

2. Mittal R, Grati $M$, Gerring $R$, et al. In vitro interaction of Pseudomonas aeruginosa with human middle ear epithelial cells. PLoS One. 2014; 9(3): e91885. doi: 10.1371/journal.pone.0091885.

3. Seid A, Deribe F, Ali K, Kibru G. Bacterial otitis media in all age group of patients seen at Dessie referral hospital, North East Ethiopia. Egypt J Ear, Nose, Throat Allied Sci [Internet] 2013; 14(2): 73-8. doi: https://doi.org/10.1016/j.ejenta.2013.02.005

4. Winn W, Allen S, Janda W, et al. Koneman's Color atlas and textbook of diagnostic microbiology. $6^{\text {th }}$ ed. Philadelphia USA: Lippincot's Williams and Wilkins; 2006, p. 211-302, 439-40.

5. Poorey VK, lyer A. Study of bacterial flora in CSOM and its clinical significance. Indian J Otolaryngol Head Neck Surg Vol 2002; 54(2): 91-5. doi: 10.1007/BF02968724.

6. Mösges $R, M$ Nematian-Samani $M$, Eichel $A$. Treatment of acute otitis externa with ciprofloxacin otic $0.2 \%$ antibiotic ear solution. Ther Clin Risk Manag. 2011; 7: 325-36.

7. Schaefer $P$, Baugh RF. Acute otitis externa: an update. Am Fam Physician. 2012; 86(11): 1055-61.

8. Li HB, Tai XH, Sang YH, et al. Association between vitamin $D$ and development of otitis media: A PRISMAcompliant meta-analysis and systematic review. Medicine (Baltimore). 2016 Oct; 95(40): e4739. doi: 10.1097/MD.0000000000004739.

9. Marom T, Marchisio P, Tamir SO, et al. Complementary and alternative medicine treatment options for otitis media a systematic review. Medicine (Baltimore). 2016; 95(6): e2695. doi: 10.1097/MD.0000000000002695.

10. Supreetha S, Mannur S, Simon SP, Jain J, Tikare S, Mahuli A. Antifungal activity of ginger extract on Candida Albicans : An In-vitro Study. J Dent Sci Res. 2011; 2(2): 18-21.

11. Benlafya K, El Farsaoui M, Chatouani S, et al. Antimicrobial potentials of aqueous and methanolic crude extracts of Zingiber officinale and Foeniculum vulgare. J Chem Pharm Res. 2015; 7(8): 964-6.

12. Riaz H, Begum A, Raza SA, et al. Antimicrobial property and phytochemical study of ginger found in local area of Punjab, Pakistan. Int Curr Pharm Journal, 2015; 4(7): 405-9. doi: https://doi.org/10.3329/icpj.v4i7.23591.

13. Hindi NKK, Al-Mahdi ZKA, Adil Z, Chabuck AG. Antibacterial activity of the aquatic extract of fresh, dry powder ginger, apple vineger extract of fresh ginger and crud oil of ginger (Zingber officinale) against different types of bacteria in Hilla city, IRAQ. Int J Pharm Pharm Sci. 2014; 6(5): 414-7.

14. Ogbonna Al, Tanko JS, Falemara BC, et al. Studies on the effects of Zingiber officinale Roscoe (Ginger) aqueous and ethanolic extracts on some fungal and bacterial species. IOSR J Pharm Biol Sci. 2014; 9(5): 1623.

15. Mošovská $S$, Nováková $D$, Kaliňák M. Antioxidant activity of ginger extract and identification of its active components. Acta Chim Slovaca. 2016; 8(2): 115-9. doi: 10.1515/acs-2015-2020.

16. Muslim NS, Nassar ZD, Aisha AFA, et al. Antiangiogenesis and antioxidant activity of ethanol extracts of Pithecellobium jiringa. BMC Compl Alternat Med. 2012; 12: $210 . \quad$ doi: https://doi.org/10.1186/1472-6882-12-210.

17. Almamory IAAS, Kamal SAA. Bacteria and fungi associated with acute otitis media. J Biol Agric Healthcare. 2014; 4(20): 41-6.

18. Khammas $A H, A b b a s ~ A K$. Isolation and identification of fungi associated with otomycosis. Iraqi J Comm Med. 2010; 3: 186-9.

19. Mansoor T, Musani MA, Khalid G, et al. Pseudomonas areugenosa in chronic suppurative otitis media: Sensitivity spectrum against various antibiotics. J Ayub Med Coll Abbottabad. 2009; 21(2): 120-3.

20. Osazuwa F, Osazuwa E, Osime C, et al. Etiologic agents of otitis media in Benin city, Nigeria. N Am J Med Sci. 2011; 3(2): 95-8. doi: 10.4297/najms.2011.395.

21. Jayakar R, Sanders J, Jones E. A study of acute otitis at Wellington Hospital, 2007-2011. Australas Med J. 2014; 7(10): 392-9. doi: 10.4066/AMJ.2014.2094.

22. Al Husaini IM, Abu-serag NA. Diagnostic study of otomycosis in Hilla city / Iraq. Int J PharmTech Res 2016; 9(9): 314-20.

23. Aremu SK, Alabi BS. Tuberculous otitis media: a case presentation and review of the literature. BMJ Case Rep. 2010; 2010: bcr0220102721. doi: 10.1136/bcr.02.2010.2721

24. Kiakojuri K, Rajabnia $R$, Jalili $B$, et al. Otomycosis in adolescent patients referred to the therapeutic centers in Babol City, Iran. Jundishapur J Microbiol. 2015; 8(5): e17138. doi: 10.5812/jjm.8(5)2015.17138.

25. Adegbiji WA, Aremu SK, Olatoke F, et al. Epidemiology of otitis Externa in developing country. Int J Recent Sci Res. 2017; 8(6): 18023-7. doi: http://dx.doi.org/10.24327/ijrsr.2017.0806.0437.

26. Ikegbunam M, Ukamaka M, Emmanuel O. Evaluation of the antifungal activity of aqueous and alcoholic extracts of six spices. Am J Plant Sci. 2016; 7(1): 11825. doi: 10.4236/ajps.2016.71013.

27. Abd El-khalek AB, El-Sayed HS, Ibrahim GA, et al. Phenolic compounds, microbial content and sensory 
evaluation of synbiotic labneh containing ginger and probiotic. Int J ChemTech Res. 2016; 9(2): 238-47.

28. Jasim A, Kumar $Y$, Benjamin J, et al. Studies on antifungal properties of some plant extracts (garlic, fenugreek, ginger) against of clinical isolate Candida species. Int J Sci Eng Technol Res. 2013; 2(19): 2180-5.

\section{Correspondence to Maha M. Mohammed}

E-mail: mahamicrobiology@yahoo.com Received Jan. $23^{\text {rd }} 2018$

Accepted Dec. $12^{\text {th }} 2018$ 